\title{
Elevated levels of numerous cytokines in drainage fluid after primary total hip arthroplasty
}

\author{
Huub J. L. van der Heide • Peter M. van der Kraan • \\ Willard J. Rijnberg • Pieter Buma $\cdot$ B. Willem Schreurs
}

Received: 7 May 2009/Revised: 20 July 2009/Accepted: 22 July 2009/Published online: 21 August 2009

(C) The Author(s) 2009. This article is published with open access at Springerlink.com

\begin{abstract}
As cytokines are involved in wound healing and other inflammatory processes, it could be valuable to measure their levels at the operative site. This study was conducted to investigate whether different cytokines are measurable in drainage fluid and, when measurable, whether we can find a difference in cytokine levels between one and six hours postoperatively. Samples from the drainage system in 30 consecutive patients undergoing primary total hip replacement were collected at one and six hours after closure of the wound. Levels of several cytokines were measured in the drainage fluids. A significant elevation of almost all cytokines was observed between the sample after one hour and six hours postoperatively. We found a strong correlation between the different pro-inflammatory cytokines. The IL-6 to IL-10 ratio were also raised, showing a pro-inflammatory predominance. Levels were much higher than those previously shown in serum.
\end{abstract}

H. J. L. van der Heide • P. Buma • B. W. Schreurs

Department of Orthopaedic Surgery,

Radboud University Nijmegen Medical Centre,

Nijmegen, The Netherlands

P. M. van der Kraan

Department of Rheumatology,

Radboud University Nijmegen Medical Centre,

Nijmegen, The Netherlands

H. J. L. van der Heide · W. J. Rijnberg

Department of Orthopaedic Surgery, Rijnstate Hospital,

Arnhem, The Netherlands

H. J. L. van der Heide $(\square)$

P.O. Box 9600, 2300 RC Leiden, The Netherlands

e-mail: h.j.l.van_der_heide@lumc.nl

\section{Introduction}

The incidence of heterotopic ossification (HO) after primary hip arthroplasty varies between $8 \%$ and $90 \%$ in literature [22]. The reason why heterotopic ossification develops is unknown, but it has been assumed that the inflammatory reaction due to the surgical trauma is the major driving force [4]. The fact that the incidence of $\mathrm{HO}$ in patients receiving non steroidal anti-inflammatory drugs (NSAIDs) after a total hip arthroplasty (THA) is much lower compared to patients not receiving NSAIDs is a confirmation of this assumption [22]. NSAIDs are still the cornerstone of HO prophylaxis, which are sometimes used in combination with radiation therapy in high risk patients $[15,23]$.

Multiple cytokines are involved in inflammatory reactions. The main pro-inflammatory cytokines interleukin- $1 \beta$ (IL-1 $\beta$ ), interleukin-6 (IL-6) and tumour necrosis factor- $\alpha$ $(\mathrm{TNF}-\alpha)$ are involved in the inflammatory response after injury [11]. After elective surgery a temporary elevation of IL-6 levels in serum or plasma has been observed [2, 9, 17, $21,25,26,28,30]$. Increased levels of Il-6 were also observed in patients having had total hip arthroplasty more then ten years previously [13]. Even more important for orthopaedic surgeons is the finding that higher IL-1 $\beta$ and TNF are also elevated in prosthetic loosening [14].

As one of the most important anti-inflammatory cytokines, elevated serum levels of interleukin 10 (IL-10) after trauma have been shown [11, 12]. For IL-10 even a positive correlation between higher levels immediately after trauma and the occurrence of sepsis later in the course was reported [12]. Most reports on the increase of cytokines after trauma or surgery are based on serum levels. There are limited data about the cytokine concentrations at the site of surgery [2, 26, 29]. However, as cytokines are very effective in cell-tocell communication [24], the concentration of cytokines 
locally at the surgical site is of major interest. Furthermore, in most studies only the pro-inflammatory cytokines are measured, resulting in a lack of knowledge about the elevation of anti-inflammatory cytokines in drainage fluid.

This study was conducted to investigate if the levels of different pro- and anti-inflammatory cytokines are measurable in drainage fluid after total hip arthroplasty and whether a difference in cytokine concentration between one and six hours postoperatively could be detected.

\section{Patients and methods}

Samples from the drainage system were collected from 30 patients following total hip arthroplasty. All patients were treated according to our local protocol which included preoperative antibiotics (cefazoline $2 \mathrm{~g}$ i.v.) and non steroidal anti-inflammatory drugs to prevent infection and heterotopic ossification, respectively. To facilitate taking samples from the standard hip drainage system a three-way connection was used. We inserted this connector, which originally is a part from a suprapubic catheter system (Cook; Limerick, Ireland), to the drain, on which we placed a three-way connector from an intravenous infusion system. A standard collection bag was placed at one end of the three-way system, while the other connection was used to collect the samples. In this way we were able to take samples from a closed suction drainage system at different time intervals instead of taking samples from the collection bag, which would have given an average of the time interval the drainage fluid was collected. Samples were taken at one and six hours after closure of the wound.

After centrifugation of the fluid at $10,000 \mathrm{rpm}$ for five minutes, the supernatant was taken and analysed using the BioPlex 17 system (Bio-Rad, Herculus, USA). GM-CSF, G-CSF, IFN- $\gamma$, TNF $\alpha$, MCP-1, IL-1beta, IL-2, IL-4, IL-5, IL-6, IL-7, IL-8, IL-10, IL-12, IL-13 and MIP-1beta levels were measured in the drainage fluids using commercially available kits according to the manufacturer's instructions (Bio-Rad, Hercules, USA). Cytokine levels were measured and analysed using the Bio-Plex system (Bio-Rad, Hercules, USA). Data were analysed using Bio-Plex Manager software. SPSS version 11.5 (SPSS Inc., Chicago, Illinois) was used for data analysis. The differences between the samples taken after one and six hours were compared using the paired sample $t$-test.

\section{Results}

In three of the 30 patients it was not possible to take samples after one hour, because the drain production was too low. In another eight patients, only one measurement was done because the wound drains clotted and stopped draining before the collection at six hours. The average drain production after one hour was $55 \mathrm{ml}(\mathrm{SD} 31 \mathrm{ml})$ and after six hours it was $268 \mathrm{ml}$ (SD $134 \mathrm{ml}$ ).

We found measurable levels of all included cytokines except IL-17 in the drainage fluid. The cytokine levels are displayed in Table 1 . We found a significant elevation of almost all cytokines between the samples after one hour and six hours postoperatively. The elevation was significant for all cytokines except IL-10 and MIP-1b. In particular, elevation in this time interval of the concentrations of IL- 6 and IL- 8 by a factor of 31.6 and 49.3, respectively, is striking. Calculating the IL-6 to IL-10 ratio, this ratio increased from 304 (SD 256) to 12,357 (SD 6788) $(p<0.000)$, which shows an increased predominance of the pro-inflammatory cytokines when comparing the measurements after one and six hours, respectively. We found a strong correlation between the different proinflammatory cytokines.

No (negative) correlation between the total drain volume and cytokine level was found, so the higher levels of cytokines are not caused by a concentration effect.

\section{Discussion}

High levels of numerous cytokines can be detected in drainage fluid after total hip arthroplasty. The levels after six hours are higher in comparison to one hour after surgery. Furthermore, the IL-6 to IL-10 ratio is increased

Table 1 Cytokine concentrations in drainage fluid

\begin{tabular}{llll}
\hline Cytokine & $\begin{array}{l}\text { Concentration } \\
\text { after 1 hour (pg) }\end{array}$ & $\begin{array}{l}\text { Concentration } \\
\text { after 6 hours (pg) }\end{array}$ & Significance \\
\hline IL-2 & 335 & 2861 & $P<0.000$ \\
IL-4 & 5,505 & 45,910 & $P<0.000$ \\
IL-6 & 313,914 & $9,916,640$ & $P<0.000$ \\
IL-8 & 10,615 & 523,257 & $P<0.000$ \\
IL-10 & 797 & 1,012 & $P=0.215$ \\
IL-1b & 498 & 8,126 & $P<0.000$ \\
IL-5 & 46 & 197 & $P<0.000$ \\
IL-7 & 551 & 965 & $P<0.000$ \\
IL-12 & 346 & 1,126 & $P<0.000$ \\
IL-13 & 103 & 560 & $P<0.000$ \\
GM-CSF & 2,285 & 22,058 & $P=0.001$ \\
IFN- $\gamma$ & 5,477 & 50,363 & $P<0.000$ \\
TNF- $\alpha$ & 1,241 & 11,559 & $P<0.000$ \\
G-CSF & 20,200 & 348,667 & $P<0.000$ \\
MCP-1 & 34,086 & 529,352 & $P<0.000$ \\
MIP-1b & 19,448 & 16,454 & $P=0.392$ \\
\hline
\end{tabular}


between these two measurements, suggesting a relative rise in the pro-inflammatory interleukins [27].

These cytokine levels were found despite the fact that all patients received NSAIDs before surgery to prevent heterotopic ossification. It would have been ideal to compare the levels of cytokines in drainage fluid in patients who did not receive NSAIDs. However, this was considered unethical due to our local protocol.

To measure cytokine levels the BioPlex 17 was used. With this system it is possible to analyse up to 100 different analytes in a single microtiter well, with a high correlation using the traditional ELISA method [6].

As it is almost impossible to measure the interstitial levels of cytokines, we believe the levels in drainage fluid are a better representation of these levels than the levels in serum. Although cytokines in general function in cell-tocell communication [24] and not at long distances, many studies describe cytokine levels in serum $[8,17,30]$. These systemic levels could represent either an over- or underrepresentation of the actual interstitial levels [24]. Weissflog et al. found a difference in cytokine levels in chest tubes, and in the same patients they did not detect a difference in the serum levels [29]. Most studies in which cytokine levels are measured both in drainage fluid and in serum show comparable results, i.e. the levels in drainage fluid are higher than in serum $[1-3,16,26]$. Furthermore, in most studies only the rise in interleukin level in the drainage fluid was significant, the levels in serum were not, or only for a subset of interleukins $[1,2,16,26]$. As proinflammatory interleukins (mainly TNF- $\alpha$, IL-1 and IL-6) initiate elaboration and release other interleukins, antiinflammatory cytokines (IL4, IL-10 and IL-13) serve to down-regulate synthesis of pro-inflammatory cytokines [11]. Taniguchi et al. [27] showed that the ratio of IL-6 and Il-10 was correlated with injury severity after major trauma and it was recommended as a useful marker to predict the degree of injury following trauma. This ratio also seems to be important in elective surgery [20]. IL-6 levels in serum correlate with disease severity and patient mortality in patients with sepsis $[5,10]$.

Di Vita et al. [7] showed that in patients who underwent surgical incisional hernia repair the local levels of cytokines differed between the group in which a mesh was used as compared to the group with a direct repair. In the group in which a mesh was implanted, the IL-1 production was higher, whereas the direct repair group showed higher levels of IL-1ra and IL-10, which are anti-inflammatory cytokines.

In mice IL- $1 \beta$ stimulates bone formation and IL- $1 \beta$ antagonist completely abolishes bone formation [19]. IL-4 and IL-13 induce bone formation and the anti-inflammatory cytokine IL-10 does not induce bone [18]. The high levels of these cytokines found in our study in the drain fluid (though not measurable in serum in former studies) can be a clue to better understanding the pathogenesis of HO. In further research it would be preferable to include a reference group not receiving any NSAIDs.

Acknowledgments We would like to thank the nurses from the Orthopaedic Department of the Rijnstate Hospital for assisting with taking the samples. Furthermore, we would like to thank M. Roelofs and L. Driessen for analysis of the samples.

Open Access This article is distributed under the terms of the Creative Commons Attribution Noncommercial License which permits any noncommercial use, distribution, and reproduction in any medium, provided the original author(s) and source are credited.

\section{References}

1. Andersson I, Tylman M, Bengtson JP et al (2001) Complement split products and pro-inflammatory cytokines in salvaged blood after hip and knee arthroplasty. Can J Anaesth 48:251-255

2. Andres BM, Taub DD, Gurkan I et al (2003) Postoperative fever after total knee arthroplasty: the role of cytokines. Clin Orthop 415:221-231

3. Baker EA, El Gaddal S, Williams L et al (2006) Profiles of inflammatory cytokines following colorectal surgery: relationship with wound healing and outcome. Wound Repair Regen 14:566-572

4. Chalmers J, Gray DH, Rush J (1975) Observations on the induction of bone in soft tissues. J Bone Joint Surg Br 57:36-45

5. Damas P, Ledoux D, Nys M et al (1992) Cytokine serum level during severe sepsis in human IL-6 as a marker of severity. Ann Surg 215:356-362

6. de Jager W, te Veldhuis H, Prakken BJ et al (2003) Simultaneous detection of 15 human cytokines in a single sample of stimulated peripheral blood mononuclear cells. Clin Diagn Lab Immunol 10:133-139

7. Di Vita G, Patti R, D'Agostino P et al (2006) Modifications in the production of cytokines and growth factors in drainage fluids following mesh implantation after incisional hernia repair. Am J Surg 191:785-790

8. Drenth JP, Van Uum SH, van Deuren M et al (1995) Endurance run increases circulating IL-6 and IL-1ra but down regulates ex vivo TNF-alpha and IL-1 beta production. J Appl Physiol 79:1497-1503

9. Frank SM, Kluger MJ, Kunkel SL (2000) Elevated thermostatic setpoint in postoperative patients. Anesthesiology 93:1426-1431

10. Frieling JT, van Deuren M, Wijdenes J et al (1995) Circulating interleukin-6 receptor in patients with sepsis syndrome. J Infect Dis 171:469-472

11. Giannoudis PV (2003) Current concepts of the inflammatory response after major trauma: an update. Injury 34:397-404

12. Giannoudis PV, Smith RM, Perry SL et al (2000) Immediate IL-10 expression following major orthopaedic trauma: relationship to anti-inflammatory response and subsequent development of sepsis. Intensive Care Med 26:1076-1081

13. Hernigou P, Intrator L, Bahrami T et al (1999) Interleukin-6 in the blood of patients with total hip arthroplasty without loosening. Clin Orthop Relat Res 366:147-154

14. Hundric-Haspl Z, Pecina M, Haspl M et al (2006) Plasma cytokines as markers of aseptic prosthesis loosening. Clin Orthop Relat Res 453:299-304

15. Kose KC, Cebesoy O, Altinel L (2007) HO prevention and the combined therapeutic protocol-do we really need it? Int Orthop 31:133-134 
16. Kristiansson M, Soop M, Sundqvist KG et al (1998) Local vs. systemic immune and haemostatic response to hip arthroplasty. Eur J Anaesthesiol 15:260-270

17. Lahat N, Zlotnick AY, Shtiller R et al (1992) Serum levels of IL-1, IL-6 and tumour necrosis factors in patients undergoing coronary artery bypass grafts or cholecystectomy. Clin Exp Immunol $89: 255-260$

18. Lind M, Deleuran B, Yssel H et al (1995) IL-4 and IL-13, but not IL-10, are chemotactic factors for human osteoblasts. Cytokine 7:78-82

19. Mahy PR, Urist MR (1988) Experimental heterotopic bone formation induced by bone morphogenetic protein and recombinant human interleukin-1B. Clin Orthop 237:236-244

20. Menger MD, Vollmar B (2004) Surgical trauma: hyperinflammation versus immunosuppression? Langenbecks Arch Surg 389:475-484

21. Miyawaki T, Maeda S, Koyama Y et al (1998) Elevation of plasma interleukin-6 level is involved in postoperative fever following major oral and maxillofacial surgery. Oral Surg Oral Med Oral Pathol Oral Radiol Endod 85:146-152

22. Neal BC, Rodgers A, Clark T et al (2000) A systematic survey of 13 randomized trials of non-steroidal anti-inflammatory drugs for the prevention of heterotopic bone formation after major hip surgery. Acta Orthop Scand 71:122-128
23. Pakos EE, Pitouli EJ, Tsekeris PG et al (2006) Prevention of heterotopic ossification in high-risk patients with total hip arthroplasty: the experience of a combined therapeutic protocol. Int Orthop 30:79-83

24. Porter JM (1999) Cytokines and pleural drainage fluid: do local levels make a difference? Chest 115:1489-1490

25. Pullicino EA, Carli F, Poole S et al (1990) The relationship between the circulating concentrations of interleukin 6 (IL-6), tumor necrosis factor (TNF) and the acute phase response to elective surgery and accidental injury. Lymphokine Res 9:231-238

26. Southern EP, Huo MH, Mehta JR et al (1995) Unwashed wound drainage blood. What are we giving our patients? Clin Orthop 320:235-246

27. Taniguchi T, Koido Y, Aiboshi J et al (1999) The ratio of interleukin-6 to interleukin-10 correlates with severity in patients with chest and abdominal trauma. Am J Emerg Med 17:548-551

28. van Deuren M, Twickler TB, Waal Malefyt MC et al (1998) Elective orthopedic surgery, a model for the study of cytokine activation and regulation. Cytokine 10:897-903

29. Weissflog D, Kroegel C, Luttmann W et al (1999) Leukocyte infiltration and secretion of cytokines in pleural drainage fluid after thoracic surgery: impaired cytokine response in malignancy and postoperative complications. Chest 115:1604-1610

30. Yamauchi H, Kobayashi E, Yoshida T et al (1998) Changes in immune-endocrine response after surgery. Cytokine 10:549-554 